\title{
STATIC, DYNAMIC AND CREEP BEHAVIOUR OF A FULL-SCALE GFRP-SFRSCC HYBRID FOOTBRIDGE
}

José A. Gonilha $^{\mathrm{a}^{*}}$, Joaquim Barros ${ }^{\mathrm{b}}$, João R. Correia ${ }^{\mathrm{a}}$, José Sena-Cruz ${ }^{\mathrm{b}}$, Fernando A. Branco ${ }^{\mathrm{a}}$, Luís F. Ramos ${ }^{\mathrm{b}}$, Delfina Gonçalves ${ }^{\mathrm{b}}$, Mário R. Alvimc, Tomé Santos ${ }^{\mathrm{c}}$

${ }^{a}$ ICIST, Department of Civil Engineering, Architecture and Georesources, Instituto Superior Técnico, Universidade de Lisboa, Av. Rovisco Pais 1, 1049-001 Lisboa, Portugal.

${ }^{\mathrm{b}}$ ISISE, Department of Civil Engineering, School of Engineering, University of Minho, Campus de Azurém, 4800-058 Guimarães, Portugal.

${ }^{c}$ ALTO, Perfis Pultrudidos, Lda. Zona Industrial da Maia I, Sector I, Rua Raimundo Durães Magalhães, Lote 20, 4475-189 Maia, Portugal.

* corresponding author: e-mail: jose.gonilha@ ist.utl.pt; tel.: (+351) 218418 430; fax.: (+351) 218418276.

Abstract: A three-year research project (Pontalumis) was carried out for the development of an innovative simply supported hybrid footbridge, with $11 \mathrm{~m}$ of length and $2 \mathrm{~m}$ of width. The footbridge is composed of two pultruded I-shaped glass fibre reinforced polymer (GFRP) girders $\left(400 \times 200(\times 15) \mathrm{mm}^{2}\right)$ bonded and bolted to a $37.5 \mathrm{~mm}$ thick deck in steel fibre reinforced self-compacting concrete (SFRSCC). The present paper describes the material/structural concept of this footbridge, its design and construction process, and summarizes the response of the prototype when submitted to static short and long-term load tests, and dynamic load tests. The prototype was simple 
and fast to execute, presenting a reduced dead-weight of only about 3 tonf. The static and dynamic behaviour of the prototype as well as its long-term deflection fulfil standards' requirements for footbridge structures and are in good agreement with conventional analytical and numerical design tools.

Keywords: GFRP pultruded profiles, steel fiber reinforced self-compacting concrete (SFRSCC), hybrid footbridge, design, construction, experimental tests.

\section{INTRODUCTION}

Recent progress on cement based materials reinforced with discrete randomly distributed fibres (generally designated fibre reinforced concrete (FRC) [1]) and on fibre reinforced polymer (FRP) materials have opened new possibilities on the development of innovative structural systems with technical and economic advantages.

Regarding FRC, the fibre reinforcement may increase significantly the tensile postcracking resistance, allowing to replace traditional (rebar) reinforced concrete (RC) with FRC in some structural applications. Experimental research on the susceptibility to corrosion of steel fibre reinforced concrete (SFRC) evidences that this phenomenon may be avoided if a thin (above $0.2 \mathrm{~mm}$ ) cement paste coating is provided to the fibres [2]. Good practices on the technology of SFRC can guarantee a cover thickness higher than this limit, even in very thin shell type elements [3], namely when using self-compacting concrete compositions, owing to the relatively high content of fine particles and paste percentage of this highly flowable mixtures [4]. The small cover thickness requirements to avoid fibre corrosion of steel fibre reinforced self-compacting concrete (SFRSCC), together with the relatively high post-cracking residual strength of this material, allow the execution 
of very thin SFRSCC elements, when compared with traditional RC elements, especially when the total thickness is governed by rebar cover requirements.

In what concerns FRP materials, namely glass fibre reinforced polymer (GFRP) pultruded profiles, they have also been increasingly used in civil engineering structural applications in the past few decades, owing to their high resistance, low self-weight, ease of installation, electromagnetic transparency and non-corrodibility [5-7]. However, GFRP members also present disadvantages that have delayed their widespread, such as the brittle failure, the high deformability, the fire behaviour and the lack of specific design codes [8-11]. In order to overcome some of these disadvantages, namely those concerning the brittle failure and the high deformability, which often leads to instability phenomena not allowing the full exploitation of the material's strength $[12,13]$, several authors have proposed hybrid GFRP-concrete structural solutions (e.g., [14-22]).

This was the main motivation of the Pontalumis research project, in which a hybrid GFRP-SFRSCC simply supported footbridge structure was idealized, where GFRP pultruded profiles act as main girders and a SFRSCC slab, laying on top of the profiles, acts as the footbridge deck. Previous studies conducted within this project comprehensively addressed, at the small scale level, very specific aspects of the structural behaviour of the GFRP-SFRSCC hybrid concept proposed, namely its static, dynamic and creep responses [22-25], as well as the interaction between GFRPSFRSSC bonded interfaces [26]. All these aspects were assessed separately using smallscale models or specimens.

Based on the results obtained in those preliminary studies, it was decided to extend the research to the full-scale level, by designing, building and testing a $11.0 \mathrm{~m}$ long hybrid GFRP-SFRSCC footbridge, which would allow investigating the practical feasibility of 
the structural system proposed, namely its manufacturing and assembly process, and would serve as a proof of concept of the structural system proposed. The first part of the present paper describes the structural solution designed for this full-scale prototype. Subsequently, the construction process adopted for the hybrid footbridge is described. The final part of the paper presents the results of a comprehensive experimental program on the full-scale prototype, which included (i) static tests; (ii) modal identification and pedestrian response tests; and (iii) creep tests. The test data are also compared with numerical and/or analytical predictions.

\section{STRUCTURAL CONCEPT}

The footbridge herein studied comprises two I-shaped $\left(400 \times 200(\times 15) \mathrm{mm}^{2}\right)$ GFRP profiles acting as main girders and a thin $37.5 \mathrm{~mm}$ thick SFRSCC deck with a width of $2000 \mathrm{~mm}$ positioned on top of the GFRP profiles, as illustrated in Figure 1. The structure presents a total length of $11000 \mathrm{~mm}$ and was tested in a $10500 \mathrm{~mm}$ simply supported span $(L)$, as shown in Figure 2.

This hybrid GFRP-SFRSCC structural system aims to fully exploit the best properties of each material. In this regard, the disposition of the elements ensures that in the longitudinal direction the SFRSCC material is subjected mainly to compressive strains, for which cementitious materials perform better, while the GFRP profiles are mostly subjected to tensile strains, for which FRP materials also present better performance. On the other hand, the GFRP pultruded profiles, being connected to the SFRSCC slab (and subjected mainly to tensile stresses), are prevented from buckling. Additionally, regarding the behaviour in the transverse direction, the SFRSCC deck ensures the transmission of the loads to the main girders without any traditional bar reinforcement, owing to its high flexural strength and 
post-cracking tensile strength, when compared to traditional concrete.

An adhesive connection between the deck and the main girders was provided, in order to ensure full interaction with minimum slip between the materials. For this purpose, an epoxy resin layer thickness of $2 \mathrm{~mm}$ was used, which had already proven to be very effective to bond FRP systems to cementitious materials [5,26]. Additionally, due to concerns regarding the long-term deterioration of the adhesive properties in consequence of rheological effects, vandalism or accidental loads, a long-term redundant mechanical connection was provided, materialized by M10 stainless steel anchors, with a spacing of $300 \mathrm{~mm}$ (2 per flange).

Secondary girders were provided to avoid the distortion of the cross-section in case of eccentric loading. These secondary girders, positioned at the support, quarterspan and midspan sections, were constituted by I-shaped $\left(200 \times 100(\times 10) \mathrm{mm}^{2}\right)$ GFRP pultruded profiles and connected to the main girders by means of equal length angle GFRP $\left(60 \times 8 \mathrm{~mm}^{2}\right)$ profiles and stainless steel bolts, threaded rods and nuts ( $c f$. Figure 2$)$.

At the support region, SFRSCC jackets were cast in-between flanges, in a length of $650 \mathrm{~mm}$ ( $c f$. Figure 2), in order to avoid premature web crippling failure of the GFRP webs under concentrated loads [20].

\section{CONSTRUCTION AND MATERIAL PROPERTIES OF THE PROTOTYPE}

\subsection{Construction of the prototype}

The construction of the footbridge prototype involved several steps, starting with the manufacturing (pultrusion) of the GFRP main and secondary girders (Figure 3a), and the assembly of the main and secondary girders, which included the drilling of the main girders, at predetermined positions, in order to accommodate the stainless steel anchors. 
The assembled girders were then transported in a regular truck to the construction site (Figure 3b). Subsequently, the SFRSCC was manufactured and the thin deck (Figure 3c) and the jackets were casted. Holes were drilled in the deck, at predetermined positions, in order to accommodate the stainless steel anchors, with a depth of $30 \mathrm{~mm}$. The stainless steel anchors were bonded to the deck with an epoxy resin (Figure 3d), with the exception of the anchors in the jackets length, which had been installed in the main girders before casting the jackets. The bonding area of the deck was roughened with a grinding machine in order to enhance the adhesive bonding and a $2 \mathrm{~mm}$ thick epoxy adhesive layer was applied (Figure 3e). The SFRSCC deck and the GFRP girders were assembled and the stainless steel nuts were screwed tight in the anchors. The prototype was kept in position for a period of 9 days to guarantee a proper curing of the epoxy adhesive (Figure 3f). Finally, the footbridge prototype was rotated $180^{\circ}$, with an auxiliary system especially designed for that purpose (Figures $3 \mathrm{~g}$ and $3 \mathrm{~h}$ ), and placed in its final position.

\subsection{Material characterization}

The GFRP profiles comprising the main and secondary girders are made of E-glass fibre rovings and mats embedded in an isophthalic polyester resin matrix and were produced by ALTO, Perfis Pultrudidos, Lda. The main mechanical properties of GFRP profiles were derived from small-scale material characterization tests, performed in coupons extracted from the flanges and webs, namely: (i) tension (EN ISO 527 [27]); (ii) compression (ASTM D 695 [28]); and (iii) shear $\left(10^{\circ}\right.$ off-axis tension tests according to the recommendations of Hodgkinson [29]) tests. These experiments allowed the determination of the longitudinal elasticity modulus in tension $\left(E_{L, t}\right)$, the transverse elasticity modulus in compression $\left(E_{T, c}\right)$, the in-plane shear modulus $\left(G_{L T}\right)$, 
the longitudinal tensile strength $\left(f_{t u, L}\right)$ and the in-plane shear strength $\left(\tau_{u, L T}\right)$ of the GFRP laminates. Table 1 summarizes the main properties of the GFRP material.

Regarding the SFRSCC, developed by CiviTest Company, Table 2 shows its mixture composition (details about the mix design are available in [3]), which incorporates $60 \mathrm{~kg} / \mathrm{m}^{3}$ of hooked end steel fibres with a length of $35 \mathrm{~mm}$, diameter of $0.55 \mathrm{~mm}$ and $1000 \mathrm{MPa}$ of tensile strength. Compressive strength and flexural properties of the SFRSCC were assessed according to the test standards NP EN 12390-3 [30] and RILEM TC 162-TDF [31], respectively, at the same age of the static tests (described in the following sections). These tests allowed the determination of the compressive strength $\left(f_{c m}\right)$, the cracking strength in flexure $\left(f_{c t, L}\right)$, the equivalent flexural tensile strengths $\left(f_{e q, 2}\right.$ and $\left.f_{e q, 3}\right)$ and the residual flexural tensile strengths $\left(f_{R, 1}\right.$ to $\left.f_{R, 4}\right)$. Table 3 summarizes the SFRSCC mechanical properties obtained. It is notable that for a crack width of $0.5 \mathrm{~mm}$ the residual flexural tensile strength of the developed SFRSCC has exceeded $10 \mathrm{MPa}$, and up to a crack with of $3.5 \mathrm{~mm}$ the decrease of this high flexural performance was almost limited to $1 \mathrm{MPa}$, revealing the high effectiveness of the fibre reinforcement. Additionally, the elasticity modulus $\left(E_{c}\right)$ was also estimated, based on the compressive strength $\left(f_{c m}\right)$ results, with Eq. (1) [32].

$$
E_{c}=22 \cdot\left[\frac{0.8 \times f_{c m}}{10}\right]^{0.3}
$$

The epoxy adhesive ( $S \& P$ Resin 220) used to bond the main girders and the deck presents average values of elasticity modulus in tension of $E_{a}=8.8 \mathrm{GPa}$ and tensile strength of $f_{a u}=17.3 \mathrm{MPa}$ [33]. The mechanical (redundant) connection was materialized by $\mathrm{M} 10 \times 55 \mathrm{~mm}$ stainless steel anchors with a bearing capacity of $f_{b k}=700 \mathrm{MPa}$ (according to the manufacturer). 


\section{STATIC BEHAVIOUR}

\subsection{Static tests}

Static load tests were performed in the footbridge prototype in order to assess its static flexural behaviour, namely the vertical deflections and the axial strains for predefined load configurations, as well as the deformation recovery after unloading.

The support conditions, which were the same in the remaining tests ( $c f$. sections 5.1, 5.2 and 6.1), comprised fixed supports on one side and sliding supports on the other, all allowing rotation around the longitudinal bending axis.

The footbridge was loaded with closed water reservoirs - each one with an average weight of $10.6 \mathrm{kN}$ and plan dimensions of $1.0 \times 1.2 \mathrm{~m}^{2}\left(8.8 \mathrm{kN} / \mathrm{m}^{2}, 76 \%\right.$ higher than the characteristic load preconized in Eurocode 1 [34] for footbridges, $5 \mathrm{kN} / \mathrm{m}^{2}$ ). The reservoirs were successively positioned with a stacker on top of the deck in three different uniformly distributed load configurations, as shown in Figure 4: (a) along the entire span, centred with the deck in a width of $1.20 \mathrm{~m}$ (total load of $106.0 \mathrm{kN}$ ); (b) in the central part of the span, in a length of about $2.70 \mathrm{~m}$ (with a small gap of $0.30 \mathrm{~m}$ in the vicinity of midspan), across the entire width of the deck $(2.00 \mathrm{~m})$ (total load of $42.2 \mathrm{kN})$; and (c) in the central part of the span, in a length of $5.10 \mathrm{~m}$ (with a gap of $0.30 \mathrm{~m}$ in the vicinity of midspan), also across the entire width of the deck (total load of $84.4 \mathrm{kN}$ ). The loading and unloading operations were performed as fast as possible in order to minimize creep effects - the duration of these operations varied between 10 and 50 minutes.

During the tests vertical deflections were measured at midspan section underneath both GFRP profiles, while axial strains were measured at different locations of that crosssection, as depicted in Figure 1. The deflections were measured with electrical transducers (precision of about $0.01 \mathrm{~mm}$ ), whereas axial strains were measured with electric strain 
gauges. Data was gathered at a rate of $1 \mathrm{~Hz}$ with data loggers and was registered in a PC. The footbridge prototype exhibited linear-elastic load-deflection and load-axial strain behaviour in all the tests during both the loading and unloading processes. Table 4 presents the average midspan deflections and axial strains measured at the end of the loading process (for each configuration), together with the numerical predictions (discussed in §4.2). The results obtained for midspan deflections and axial strains are in agreement with linear elastic structural analysis: (i) deflections/axial strains for load configuration (b) were around half of those for configuration (c) (similar configurations were used and the load in (c) was twice of that used in (b)); (ii) deflections/axial strains for load configuration (a) were lower than those for configuration (c) (a higher total load was used in (a), but in (b) loads were concentrated in the vicinity of midspan). Regarding the unloading process, the small residual deflections of $4.52 \%, 0.98 \%$ and $4.10 \%$ for load configurations (a), (b) and (c), respectively, may have been caused by (i) some initial accommodation of the support system and/or (ii) the initial creep developed during the loading process (although the authors tried to complete this process in the shortest period of time).

\subsection{Numerical modelling}

\subsubsection{Model description}

To simulate the structural behaviour of the footbridge prototype observed in the experimental tests, a finite element (FE) model was developed using the commercial package SAP2000. The model included 8-node solid brick elements in order to simulate most structural components, namely: (i) the SFRSCC deck; (ii) the $2 \mathrm{~mm}$ thick epoxy adhesive layer; (iii) the GFRP main girders; (iv) the GFRP secondary girders, (v) the 
steel support plates, and (vi) the GFRP angle sections ( $c f . \S 3.1$ ). Two-joint link elements were also used to simulate the mechanical connections between main and secondary girders and to connect the support sections to the rotation centre of the supports.

The material properties considered were those obtained from experimental coupon testing ( $c f$. §3.2). The GFRP profiles were modelled as orthotropic materials (a Poisson coefficient of $v_{\mathrm{LT}}=0.275$ was considered) and the remaining ones as isotropic. Figure 5 shows a view of the 3-dimensional model of the footbridge prototype. A perfect bond was assumed at the GFRP-epoxy and SFRSCC-epoxy interfaces, i.e. only the adhesive distortion was considered. This modelling approach is supported by pull-off tests carried out within this project (e.g., [26]) and validated by the present test results, namely the axial strains measured throughout the depth of the hybrid section.

The static tests were simulated by applying surface pressure loads in the top elements of the deck with the geometry of each load configuration described in $\S 4.1$. To this end, a linear elastic analysis was performed as all materials behaved within their linear elastic range.

An additional analysis was performed to simulate the failure behaviour of the prototype. In this case, two different uniformly distributed load configurations were defined: (i) load applied on the entire deck surface; and (ii) load applied over half of the deck width (to assess the torsional effects). Owing to the fact that, at failure, the stresses in the SFRSCC deck are still within the elastic branch of the material behaviour ( $c f$. Section 4.2.2), the failure behaviour analyses were also linear elastic, using the Tsai-Hill failure criterion to determine the GFRP failure initiation.

\subsubsection{Numerical results}


Table 4 compares the experimental and numerical results for each load configuration, regarding the average midspan deflections, axial strains and cross-section curvature $(\chi)$. Results obtained show an excellent agreement between the average midspan deflections predicted by the FE model and those measured in the tests, with a maximum relative difference of $3.3 \%$ among the three load configurations. Regarding the average axial strains, the agreement between numerical results and experimental data was very good to reasonable, with a maximum relative difference of $33 \%$; however, in general, the relative differences were lower than $12 \%$. It should be noted that these results refer to relatively low axial strains and that the measurement of axial strains is typically less precise than that of deflections (especially in concrete due to its granular nature). Furthermore, it is worth mentioning that very reduced relative differences (maximum of 7\%) were registered regarding the midspan cross-section curvature. Overall, these results show that the FE model is able to simulate the static flexural behaviour of the hybrid structure with excellent accuracy.

The failure analyses showed that, for both load configurations (i.e., load applied in the entire deck or in half of its width), failure initiation occurred in the webs of the GFRP main girders for a load of $22.84 \mathrm{kN} / \mathrm{m}^{2}$ and $20.71 \mathrm{kN} / \mathrm{m}^{2}$ (plus self-weight), respectively. For both load configurations, failure occurred at a distance of $650 \mathrm{~mm}$ from the support sections, near the web-flange junction. Additionally, for both cases, the maximum tensile stress in the SFRSCC is lower than $6 \mathrm{MPa}\left(<\mathrm{f}_{\mathrm{ct}, \mathrm{L}}\right)$, while the maximum compressive stress is lower than $35 \mathrm{MPa}\left(<0.5 \times \mathrm{f}_{\mathrm{cm}}\right)$, well within the elastic branch of the material behaviour. It is also worth noting that the governing load configuration corresponded to the load applied in half of the deck width, attesting the importance of torsion loads on this type of structural system. The failure load predicted 
by the FE model corresponds to $\approx 414 \%$ of the characteristic load specified by Eurocode 1 [34] for footbridges $\left(5 \mathrm{kN} / \mathrm{m}^{2}\right)$.

\section{DYNAMIC BEHAVIOUR}

\subsection{Modal Identification tests}

A modal identification test was carried out to estimate the natural frequencies, mode shapes and damping ratios of the prototype. This test was performed by measuring vertical and transverse structural accelerations for time periods of 5 minutes, during which small impact loads were induced in the footbridge deck, at random nature, with a rubber hammer with medium-soft tip. Accelerations were measured in 18 different positions along the edges of the deck, as depicted in Figure 6. Since the number of measuring points was higher than the number of available measuring sensors (14), three test setups were devised, as shown in Figure 6, keeping three reference sensors (Ac1, Ac2 and Ac3) at the same position and orientation.

The structural accelerations were measured with piezoelectric accelerometers with a sensitivity of $10 \mathrm{~V} / \mathrm{g}$ and a range of $\pm 0.5 \mathrm{~g}$. Data was gathered with a data logger at a rate of $200 \mathrm{~Hz}$ and registered in a PC. During the test, amplitudes of motion were under $0.3 \mathrm{~g}$, as shown in Figure 7 for test setup 1 (as an example), while several clear peaks could be observed between 6 and $90 \mathrm{~Hz}$, as can be depicted from Figure 8 for the same test setup (also as an example).

The Enhanced Frequency Domain Decomposition (EFDD) method was used to estimate the dynamic parameters [35]. Figure 9 shows the results of these analyses in terms of mode shape configurations, while Table 5 summarizes the resonant frequencies, damping ratios and nature of the identified modes. In total 16 mode shapes were identified, 
including vertical and lateral bending modes and torsion modes. It should be stressed that not all modes present clear symmetry axis ( $c f$. Figure 9 and Table 5). These unexpected results are due to slight differences, more evident for modes 6 to 10 , in the modal displacements registered at quarterspan of the footbridge. The asymmetric modal behaviour may be due to (i) geometric deviations introduced during the construction of the bridge and/or (ii) the presence of micro-cracks on the SFRSCC detected in the vicinity of one of the quarterspans. These micro-cracks may have been formed due to the shrinkage phenomenon. Their magnitude was assessed with a digital handle microscope, the average value of the crack width being about $0.06 \mathrm{~mm}$.

Concerning the quality of the modal estimates, in general, the coefficient of variation $(\mathrm{CoV})$ for frequency was lower than $1 \%$, with exception of modes 4 and 5 (cf. Table 5). The damping ratios estimates presented a higher variability, however, an average damping ratio of $0.95 \%$ with a $\mathrm{CoV}$ of $20 \%$ could be established.

Given the high variation obtained in the damping estimates with the EFDD method, a free vibration test, carried out by suddenly releasing the structure from a static load, was performed in order to provide a better damping estimation. This test was performed by having a pedestrian (weighing approximately $90 \mathrm{kgf}$ ) jumping off the deck at midspan. The transient response was measured in the reference positions used in the previous test (Ac1, Ac2 and Ac3, cf. Figure 6) and is plotted in Figure 10. Using the logarithm decrement method, the global damping ratio of the footbridge was estimated as $1.05 \%$, thus validating the results obtained with the EFDD method.

\subsection{Pedestrian response tests}

The design of footbridge structures is often govern by serviceability requirements 
concerned with pedestrian comfort criteria [23,36-37]. These requirements are more difficult to be fulfilled in slender structures, such as the present footbridge that exhibits geometric slenderness and incorporates relatively flexible materials (GFRP). Thereafter, the assessment of the structural behaviour of this type of structures under pedestrian loads is of great importance. In this context, two sets of dynamic tests under pedestrian loads were performed: (i) tests with one pedestrian; and (ii) tests with several pedestrians simulating a crowd ( 6 to 7 pedestrians $-\sim 0.3$ pedestrians $/ \mathrm{m}^{2}$ ). Figure 11 shows these tests in progress. For both sets of tests, vertical accelerations were measured at quarter- and midspan sections near the cantilevers, as shown in Figure 12, with a pair of equivalent piezoelectric accelerometers (sensitivity of $98 \mathrm{pC} / \mathrm{g}$ and range of $\pm 98 \mathrm{~g}$ ). Data was sampled at a rate of (i) $600 \mathrm{~Hz}$ for one-pedestrian tests, and (ii) $200 \mathrm{~Hz}$ for the crowd tests, by using a data logger connected to a PC.

One-pedestrian tests were performed by measuring the vertical accelerations at the previously referred positions, while one pedestrian (weighing $85 \mathrm{kgf}$ ) crossed the footbridge deck in a centred or eccentric path ( $c f$. Figure 12) at different walking paces: (i) slow; (ii) normal; (iii) fast and; and (iv) run. Figure 13 presents, as an example, the accelerations at position A1 when the pedestrian walked normally in the centred and eccentric paths. Table 6 summarizes the maximum vertical accelerations registered in this set of tests. The results obtained show that the maximum value for vertical acceleration specified in Eurocode 0 [38] $\left(0.70 \mathrm{~m} / \mathrm{s}^{2}\right)$ is generally not reached - the only exception was the maximum acceleration at position A1 when the pedestrian ran over the cantilever. Note that this maximum acceleration refers to a single peak value that does not fully represent the overall response of the structure and is deemed to have little influence on the comfort of pedestrians travelling along the footbridge. It is worth mentioning that for the particular case under study, for 
which the frequency of the fundamental vibration mode $(6.40 \mathrm{~Hz})$ is higher than $5.0 \mathrm{~Hz}$, Eurocode 0 [38] does not require the direct assessment of maximum accelerations. The fulfilment of this condition seems to be in agreement with the relatively low values of maximum accelerations (that exceeded the $0.70 \mathrm{~m} / \mathrm{s}^{2}$ limit in a very particular single case). In the crowd tests a group of 6 to 7 pedestrians (average weight of $85.1 \mathrm{kgf}$ ) travelled along the footbridge at random speeds and paths for a period of about 5 minutes, while vertical accelerations were measured at positions A1 to A4 (cf. Figure 12). The accelerations measured in these tests were transformed from the time domain to root mean squared (RMS) accelerations in the frequency domain, allowing the comparison with the limits indicated in ISO 10137 [39], which, unlike the pedestrian comfort criteria specified in Eurocode 0 [38], account for the frequency of the structural response on the pedestrian comfort level, considering the overall response as well as the period of exposure to the vibrations, thereby setting different limits for different structural uses.

Figure 14 compares the limits of ISO 10137 [39] with the structural response measured in the crowd tests. This comparison was set for a person standing still in the footbridge while another pedestrians travels along it (the most severe situation for footbridges) for different times of exposure. The obtained results show that there is very low probability of pedestrian discomfort except for an exposure period over 16 hours, which naturally is not expected in an $11 \mathrm{~m}$ long footbridge.

\subsection{Numerical simulation of the dynamic characteristics}

The previously mentioned FE model $(c f . \$ 4.2)$ was used to predict the dynamic characteristics of the footbridge, namely regarding its vibration frequencies and mode shapes. In this context, the FE model was used to determine the first 6 vibration modes. 
Table 5 summarizes the predictions obtained with the FE model and compares them with the experimental estimates.

The FE model predicted with good accuracy the mode shapes and frequencies of the first two modes, when compared to the experimental estimates, but failed to predict the existence of a lateral bending mode in this frequency range $\left(3^{\text {rd }}\right.$ mode observed experimentally, $c f$. Table 5). However, the $3^{\text {rd }}$ vibration mode may stem from geometry deviations introduced during the construction, by the small cracking observed in the footbridge deck (mentioned earlier) or even from the inability of the support system to fully restrain very small lateral displacements, the effects of which cannot be predicted by a linear-elastic FE model. With the exception of the $3^{\text {rd }}$ experimental mode, which could not be predicted, due to the aforementioned reasons, the FE model continued to predict with good accuracy the next relevant mode shapes and frequencies.

\section{CREEP BEHAVIOUR}

\subsection{Experimental test}

To assess the flexural creep behaviour of the footbridge prototype, a flexural creep test was performed by applying an uniformly distributed loaded materialized by 80 cement bags (each one weighing $40 \mathrm{kgf}$ ) placed on the top surface of the SFRSCC deck, as shown in Figure 15. Therefore a total load of $31.4 \mathrm{kN}$, equivalent to $1.49 \mathrm{kN} / \mathrm{m}^{2}$, was applied, which is approximately $30 \%$ of the characteristic live load for footbridges defined in Eurocode 1 [34]. Midspan deflections underneath both main girders were measured with analogical deflection gauges (precision of $0.001 \mathrm{~mm}$ ), during the loading process (which lasted approximately 30 minutes), and up to 3670 hours ( $\approx 153$ days) after the loading process was completed. During the test period, the air temperature $(T)$ and the relative humidity $(R H)$ in the surroundings of the footbridge were also measured, as depicted in Figure 16. 
Figure 17 shows the average creep deflections (results were very consistent for both girders) measured after the loading process has been concluded, together with the Findley's power law ( $c f$. Eq. (2)) regression (commonly used to predict the creep behaviour of FRP materials [40]),

$$
\Delta(t)=\Delta_{0}+m \cdot t^{n}
$$

where $\Delta(t)$ is the time-dependent general deformation (strain or deflection), $\Delta_{0}$ is the instantaneous general deformation, $t$ is the time, $m$ is a stress-dependent coefficient, and $n$ is a stress independent coefficient.

Applying Eq. (2) to the experimental results (average midspan deflections) a good fitting to the experimental results is obtained $\left(R^{2}=0.963\right)$ with $m=0.945$ and $n=0.197$, as depicted in Figure 17. The experimental observations show that the average creep deflection at the end of the test was $4.71 \mathrm{~mm}$, which corresponds to a $39.9 \%$ increase of the instantaneous deflection. The Findley's power law prediction for the creep deflection at the end of the test $(4.75 \mathrm{~mm})$ agrees well with the experimental result $(+0.8 \%)$.

\subsection{Analytical modelling}

To predict the deflections of GFRP-concrete hybrid structures the shear deformations must be duly accounted [41]. Therefore, in this type of structures, the deflections shall be calculated using Timoshenko's beam theory. In this particular case, the mid-span deflections of the simply supported footbridge caused by a uniformly distributed load $(q)$ may be computed with the following equation,

$$
\delta_{\text {mid-span }}=\frac{5 \cdot q \cdot L^{4}}{384 \cdot E I}+\frac{q \cdot L^{2}}{8 \cdot G k A}
$$

where, $L$ is the span, and $E I$ and $G k A$ are, respectively, the flexural and shear stiffness of the cross-section. The flexural stiffness may be computed based on the following 
assumptions: (i) the effective width of the slab is calculated using the formulae presented in Eurocode 4 [42] for steel-concrete hybrid structures - which in this case resulted in the consideration of the whole width of the SFRSCC slab; (ii) no slip is considered in the GFRP-SFRSCC interface, according to the results of shear connection tests performed previously [43]; and (iii) the stiffness provided by the $2 \mathrm{~mm}$ thick adhesive layer is disregarded, with a $2 \mathrm{~mm}$ gap being considered between the GFRP profiles and the SFRSCC slab. Regarding the calculation of the shear stiffness, the shear area $(k A)$ may be assumed as the cross-section of the GFRP webs $\left(A_{w}\right)$, a common (and conservative) assumption for FRP structures [19-21].

The instantaneous midspan deflection of the footbridge subjected to the load applied in the creep tests $\left(q=1.49 \mathrm{kN} / \mathrm{m}^{2}\right)$ computed with Eq. (3) is $11.24 \mathrm{~mm}$ (flexure accounts for $95.9 \%$ of this figure), which agrees very well with the experimental result $(-4.9 \%)$. Equation (3) can also be used to determine the creep deflections. For this purpose, the instantaneous stiffness ( $E I$ and $G k A)$ must be replaced by the time-dependent stiffness: (i) $E I(t)$, for flexure, and (ii) $G(t) k A$ for shear.

The elasticity modulus of the SFRSCC as a function of time may be determined from the well-known equations proposed in Eurocode 2 [32] for concrete. Regarding the GFRP material, it has been recently proposed that the time-dependent elasticity and shear moduli shall be chosen according to the stress state of the FRP material [25]. In the present case, the neutral axis lays in the GFRP profiles' webs $(62.98 \mathrm{~mm}$ from the top surface of the deck), which means that the GFRP profile is subjected to flexure, while the SFRSCC slab is entirely under compression. Thereafter, the time-dependent moduli in flexure proposed by Bank [41] are used, duly adjusted in order to account for the effects of temperature, according to the recommendations of Dutta and Hui [44] set for Findley's law based creep 
models. Finally, the time-dependent moduli may be computed with the following equation [25],

$$
\begin{aligned}
& E(t, T)=\frac{E_{0}}{1+\left(E_{0} / E_{t}\right) t^{n_{E}\left(T / T_{0}\right)}} \\
& G(t, T)=\frac{G_{0}}{1+\left(G_{0} / G_{t}\right) t^{n_{G}\left(T / T_{0}\right)}}
\end{aligned}
$$

where, $E_{0}$ and $G_{0}$ are the instantaneous elasticity and shear moduli, respectively, $E_{t}$ and $G_{t}$ are the elasticity and shear creep moduli, respectively, $n_{E}$ and $n_{G}$ are Findley's law stressindependent parameters for bending and shear ( $c f$. (Eq. (2)), $T$ is the temperature (constant) and $T_{0}$ is the reference temperature (which may be taken as $25^{\circ} \mathrm{C}$ [44]).

For situations in which the temperature is not constant (the variation of the temperature during the creep test was relatively high, $c f$. Figure 16), the authors propose to correct the slope of the time-dependent moduli $(E(t)$ or $G(t))$ taking into account the temperature variation according to the following equation:

$$
\begin{array}{ll}
E(t)=E\left(t_{i-1}\right)+\left[\left(E\left(t, T_{i}\right)-E\left(t_{i-1}, T_{i}\right)\right]\right. & , t_{i-1}<t \leq t_{i} \\
G(t)=G\left(t_{i-1}\right)+\left[\left(G\left(t, T_{i}\right)-G\left(t_{i-1}, e_{i}\right)\right],\right. & t_{i-1}<t \leq t_{i}
\end{array}
$$

This equation considers a time-step ranging from $t_{i-1}$ to $t_{i}$, for which an average temperature $T_{i}$ is registered. Within a given time step, the elasticity (or shear) modulus is obtained by adding the elasticity (shear) modulus at the beginning of the time-step $\left(E\left(t_{i-1}\right)\right.$, known a priori) to the elasticity (shear) modulus variation at that given age and average temperature (e.g., $\left(E\left(t, T_{i}\right)-E\left(t_{i-1}, T_{i}\right)\right.$, obtained from Eq. (4)). Therefore, a continuous curve is obtained for the time-dependent moduli, albeit their slope may present local discontinuities due to temperature variations.

For the flexural creep behaviour, Bank [41] proposes $E_{t}=1241.06 \mathrm{GPa}, G_{t}=186.16 \mathrm{GPa}$, 
and $n_{E}=n_{G}=0.30$. These parameters are highly dependent on the FRP material used, namely on its (i) fibre architecture; (ii) type of resin, and (iii) curing process. In fact, a review $[5,40]$ of several studies regarding the creep response of GFRP flexural members has shown that the $n_{E}$ parameter may range from 0.30 to 0.36 . In this context, and given the relatively short curing period of the GFRP material (performed at ambient temperature), the authors decided to perform a sensitivity analysis on the parameters governing the time-dependent elasticity modulus, namely on (i) the $n_{E}$ parameter, varying between 0.30 (proposed by Bank [41]) and $0.36(+20 \%)$ [40,45], and (ii) the $E_{t}$ parameter, ranging from 1241.06 GPa (proposed by Bank [41]) and 992.85 GPa (-20\% - a similar variation to that of the previous parameter). The shear creep parameters considered were those suggested by Bank $\left(G_{t}=186.16 \mathrm{GPa}, n_{G}=0.30\right)[41]$.

Figure 17 compares the analytical predictions with the experimental results in terms of midspan deflection. The analytical predictions were performed considering the temperature variations observed experimentally within 5 minute periods ( $c f$. Eq. (5)). The average $R H$ of 72.5\% observed in the tests was considered for the calculation of the time-dependent elasticity modulus of the SFRSCC. Figure 17 shows that the experimental results are well within the sensitivity analysis performed. It can also be seen that the initial experimental measurements (up to 1000 hours) are very well described by the GFRP creep model with $\mathrm{n}_{\mathrm{E}}=0.36$ and $E_{t}=992.85 \mathrm{GPa}$, which are respectively higher and lower than the corresponding values proposed by Bank [41]. Subsequently, and up to the end of the test, the experimental data lie between the above mentioned modelling curve and that with $\mathrm{n}_{\mathrm{E}}=0.36$ and $E_{t}=1241.06 \mathrm{GPa}$. In spite of the variation exhibited by the experimental data between 2300 and 2600 hours, which may be due to the environmental conditions, namely the relative humidity (whose average increased at this stage and is not accounted for in the 
GFRP creep model), results obtained in this study show that for the GFRP material tested a general better agreement is achieved with $n_{E}=0.36$ and $E_{t}=992.85 \mathrm{GPa}$.

Regarding the long-term predictions, Figure 18 presents the predictions of midspan deflections up to 100 years based on (i) Findley's power law (fitted with the experimental data), and (ii) the analytical model proposed by the authors (considering the average temperature $\left(16.91^{\circ} \mathrm{C}\right)$ and $R H(72.5 \%)$ measured in the creep test). These results show that the creep deformations predicted with Findley's power law deviate considerably from those obtained with the analytical model (for the various combinations of creep parameters). While Findley's power law prediction indicates an overall deflection of $25.8 \mathrm{~mm}$ after 100 years (more than twice the instantaneous deflection), the other analytical predictions range from $16.2 \mathrm{~mm}$ to $20.5 \mathrm{~mm}(+44 \%$ to $+82 \%$ higher than the instantaneous deflection), which corresponds to L/648 and L/512, respectively.

Regarding the use of Findley's power law to predict long-term deformations of GFRPconcrete structures, although the results presented here have shown a good adjustment between such law to the experimental results, previous investigations performed by some of the authors [25] indicate that using Findley's power law, based on short-term test results, may lead to unrealistic predictions of long-term deformations for GFRP-concrete hybrid structures. This has been attributed to (i) the nature of the creep response of the SFRSCC material (not complying with Findley's power law) and (ii) the changes in the neutral axis of the section that may change the logarithmic slope of the curve representing the structural response ( $n$ parameter), which is constant in Findley's power law.

The obtained results, namely the high sensitivity of long-term deflections to $n_{E}$ and $E_{t}$ parameters, also stress the importance of defining reliable creep parameters for the GFRP material. In this regard, manufacturers should provide these very important material 
properties, moreover since the design of most FRP structures is governed by deformability restrictions.

\section{CONCLUDING REMARKS}

This paper summarized the most relevant features about the conception, design, construction and testing of an $11 \mathrm{~m}$ long hybrid footbridge, with a total dead-weight of about 3 tonf. The structure comprises two longitudinal I-section GFRP main girders $\left(200 \times 400(\times 15) \mathrm{mm}^{2}\right)$, connected to a $2000 \mathrm{~mm}$ wide and $37.5 \mathrm{~mm}$ thick SFRSCC deck with a $2 \mathrm{~mm}$ thick layer of epoxy adhesive and M10 stainless steel anchors. The SFRSCC was designed to limit the crack width to $0.2 \mathrm{~mm}$ for all the design conditions for this type of application, and has presented a post-cracking residual strength at $0.5 \mathrm{~mm}$ and $2.5 \mathrm{~mm}$ of about $10 \mathrm{MPa}$, with a cost of about $120 € / \mathrm{m}^{3}$, which is more competitive than using conventional reinforced concrete $(70 \mathrm{~mm}$ of thickness with steel flexural reinforcement, which would require stiffer/larger GFRP girders due to the higher dead-weight of the deck). The static tests performed for several loading configurations attested the adequate structural response of the hybrid footbridge, showing that it fulfils the deflection requirements for serviceability limit states. The experimental responses were accurately predicted using FEMbased models considering elastic behaviour for the constituent materials.

The modal identification tests, complemented with the EFDD method, allowed determining the modal parameters, including the global damping ratio, which was estimated between $0.95 \%$ and $1.05 \%$. The numerical model developed was able to predict the most relevant vibration mode shapes and frequencies. The dynamics tests under pedestrian loads showed that there is very low probability of pedestrian discomfort due to the structural vibrations, except for an exposure period over 16 hours, which naturally is 
not expected in an $11 \mathrm{~m}$ long footbridge.

In the flexural creep test the instantaneous deflection increased by approximately $40 \%$ after 5 months. An analytical model was proposed to predict the long-term deflections of this type of hybrid structures, which considers the flexural and shear stiffness of the structural system, including the environmental temperature-dependent long-term moduli of the materials involved.

Overall, the results of this project confirmed the potential of the proposed hybrid GFRPSFRSCC structural system for footbridge applications. Furthermore, the numerical and analytical models were able to predict the static and dynamic responses with very good accuracy, showing that this type of structure can be designed with design tools that are readily available for structural engineers.

\section{NOMENCLATURE}

\section{Symbol Description}

$A_{w} \quad$ area of the GFRP webs

$E(t) \quad$ Time-dependent elasticity modulus

$E_{0} \quad$ Instantaneous elasticity modulus

$E_{a} \quad$ elasticity modulus in tension of the epoxy adhesive

$E_{c} \quad$ elasticity modulus in compression of the SFRSCC

EI flexural stiffness of the cross-section

$E I(t)$ Time-dependent flexural stiffness of the cross-section

$E_{L, t} \quad$ elasticity modulus in tension of the GFRP for the longitudinal direction

$E_{t} \quad$ Creep elasticity modulus

$E_{T}(t) \quad$ Time-dependent elasticity modulus considering temperature $T$

$E_{T, c} \quad$ elasticity modulus in compression of the GFRP for the transverse direction

$f_{a u} \quad$ tensile strength of the epoxy adhesive

$f_{b k} \quad$ characteristic tensile strength of the stainless steel bolts

$f_{c m} \quad$ compressive strength of the SFRSCC 


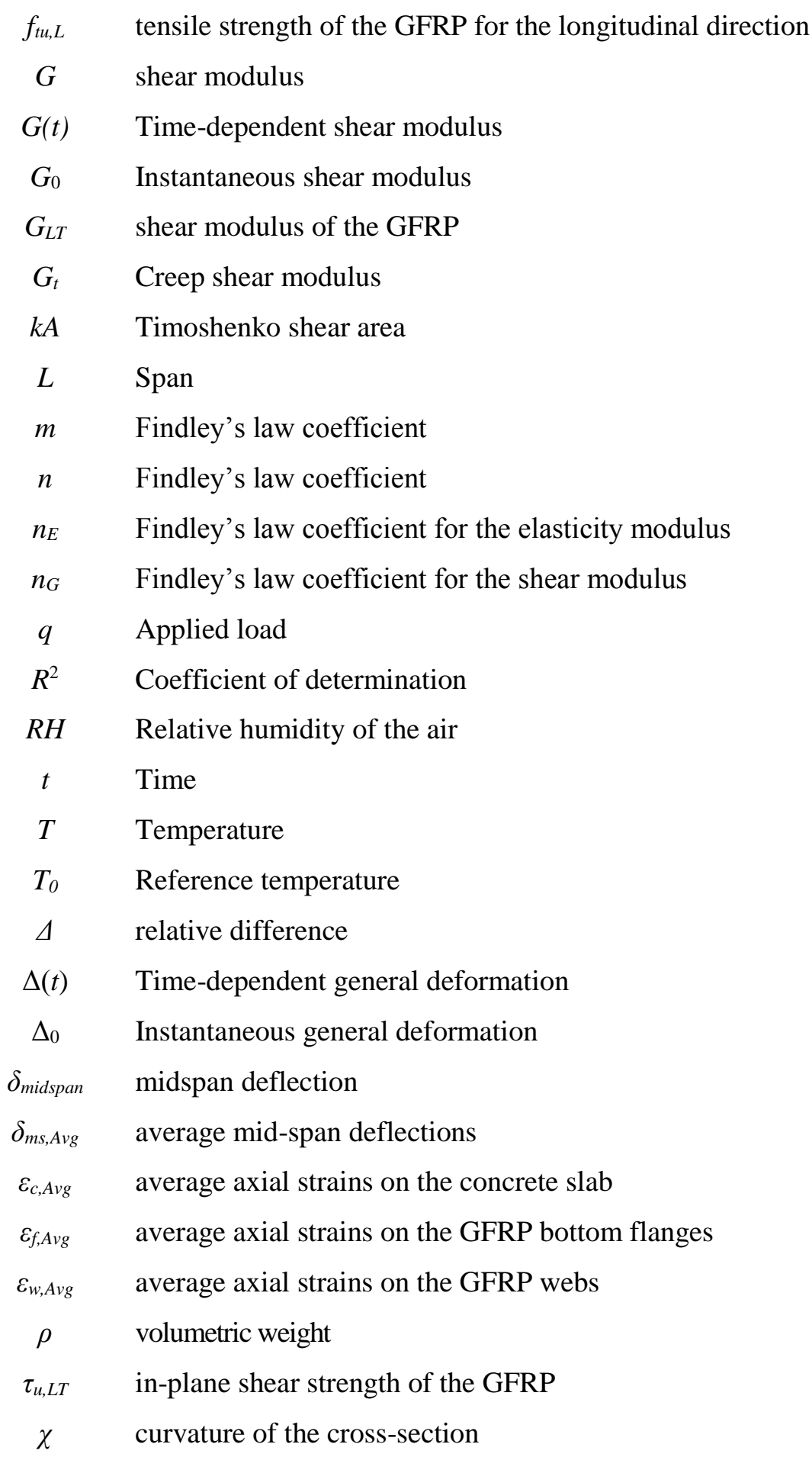

\section{ACKNOWLEDGEMENTS}

This work is part of the research project PONTALUMIS - Development of a prototype of a pedestrian bridge in GFRP-ECC, involving ICIST/Instituto Superior Técnico, 
ISISE/University of Minho and company ALTO - Perfis Pultrudidos, Lda.. The authors would like to acknowledge ICIST, ISISE, FCT and ADI (project 2009/003456) for the financial support, ALTO Perfis Pultrudidos, Lda. for supplying the GFRP pultruded profiles, SIKA, S\&P Clever Reinforcement and INTEC for supplying the other materials used in the experiments, and Tecnipor for providing the SFRSCC and helping in the construction of the prototype. The first author is also grateful to FCT for funding his research through scholarship SFRH/BD/70041/2010.

\section{REFERENCES}

[1] Barros JAO. Technology, design and applications of steel fibre reinforced selfcompacting concrete. $6^{\text {th }}$ International Conference Fibre Concrete 2011 - Conference Proceedings, Prague, 2011.

[2] Balouch S, Forth J, Granju J. Surface corrosion of steel fibre reinforced concrete. Cement and Concrete Research 2010; 40(3): 410-414.

[3] Barros JAO, Pereira EB, Santos SPF. Lightweight panels of steel fiber reinforced self-compacting concrete. ASCE Materials in Civil Engineering Journal 2007; 19(4): 295-304.

[4] Pereira ENB. Steel Fibre Reinforced Self-compacting Concrete: from material to mechanical behaviour, dissertation for Pedagogical and Scientific Aptitude Proofs, Department Civil Engineering, University of Minho, 2006.

[5] Correia JR. GFRP Pultruded Profiles in Civil Engineering: Hybrid Solutions, Bonded Connections and Fire Behaviour, $\mathrm{PhD}$ Thesis in Civil Engineering, Instituto Superior Técnico, Technical University of Lisbon; 2008.

[6] Liao K, Schultheisz CR, Hunston DL. Effects of environmental aging on the 
properties of pultruded GFRP. Composites Part B: Engineering 1999; 30(5): 485-493.

[7] Cabral-Fonseca S, Correia JR, Rodrigues MP, Branco FA. Artificial Accelerated Ageing of GFRP Pultruded Profiles Made of Polyester and Vinylester Resins: Characterization of Physical-Chemical and Mechanical Damage. Strain 2012; 48(2): $162-173$.

[8] Keller T, de Castro J. System ductility and redundancy of FRP beam structures with ductile adhesive joints. Composites Part B: Engineering 2005; 36(8): 586-596.

[9] Feo L, Mosallam AS, Penna R. Mechanical behavior of web-flange junctions of thin-walled pultruded I-profiles: An experimental and numerical evaluation. Composites Part B: Engineering 2013; 48: 18-39.

[10] Correia JR, Branco FA, Ferreira JG, Bai Y, Keller T. Fire protection systems for building floors made of pultruded GFRP profiles: Part 1: Experimental investigations. Composites Part B: Engineering 2010; 41(8): 617-629.

[11] Correia JR, Branco FA, Gonilha JA, Silva N, Camotim D. GFRP Pultruded Flexural Members: Assessment of Existing Design Methods. Structural Engineering International 2012; 20(4): 362-369.

[12] Correia JR, Branco FA, Silva N, Camotim D, Silvestre N. First-Order, Buckling and Post-Buckling Behaviour of GFRP Pultruded Beams Part 1: Experimental Study”. Computers and Structures 2011; 89(21-22): 2052-2064.

[13] Ascione L, Giordano A, Spadea S. Lateral buckling of pultruded FRP beams. Composites Part B: Engineering 2011; 42(4): 819-824.

[14] Deskovic N, Triantafillou T, Meier U. Innovative design of FRP combined with concrete: Short-term behaviour. Journal of Structural Engineering 1995; 121(7): 10691078. 
[15] Hall JE, Mottram JT. Combined FRP reinforcement and permanent formwork for concrete members. Journal of Composites for Construction 1998; 2(2): 78-86.

[16] Fam AZ, Rizkalla SH. Flexural behavior of concrete-filled fiber-reinforced polymer circular tubes. Journal of Composites for Construction 2002; 6(2): 123-131.

[17] Hulatt J, Hollaway L, Thorne AM. The use of advanced composites to form an economic structural unit. Construction and Building Materials 2003; 17(1): 55-68.

[18] Keller T, Schaumann E, Vallée T. Flexural behavior of a hybrid FRP and lightweight concrete sandwich bridge deck. Composites Part A: Applied Science and Manufacturing 2007; 38(3): 879-889.

[19] Correia JR, Branco FA, Ferreira JG. Flexural behaviour of GFRP-concrete hybrid beams with interconnection slip. Composite Structures 2007; 77(1): 66-78.

[20] Correia JR, Branco FA, Ferreira JG. GFRP-concrete hybrid cross-sections for floors of buildings. Engineering Structures 2009; 31(6): 1331-1343.

[21] Correia JR, Branco FA, Ferreira JG. Flexural behaviour of multi-span GFRPconcrete hybrid beams. Engineering Structures 2009; 31(7): 1369-1381.

[22] Gonilha JA, Correia JR, Branco FA. Structural behaviour of a GFRP-concrete hybrid footbridge prototype: Experimental tests and numerical and analytical simulations. Engineering Structures 2014: 11-22.

[23] Gonilha JA, Correia JR, Branco FA. Dynamic response under pedestrian load of a GFRP-SFRSCC hybrid footbridge prototype: Experimental tests and numerical simulation. Composite Structures 2013; 95: 453-463.

[24] Gonilha JA, Correia JR, Branco FA, Caetano E, Cunha A. Modal identification of a GFRP-concrete hybrid footbridge prototype: Experimental tests and analytical and numerical simulations. Composite Structures 2013; 106: 724-733. 
[25] Gonilha JA, Correia JR, Branco FA. Creep response of GFRP-concrete hybrid structures: application to a footbridge prototype. Composites: Part B 2013; 53: 193-206. [26] Mendes PJD, Barros JAO, Sena-Cruz JM, Taheri M. Influence of fatigue and aggressive exposure on GFRP girder to SFRC deck all-adhesive connection. Composite Structures 2014; 110: 152-162.

[27] ISO 527:1997. Plastics - Determination of tensile properties. International Organization for Standardization (ISO), Genève; 1997.

[28] ASTM D 695. Standard test method for compressive properties of rigid plastics. American Society for Testing and Materials (ASTM), West Conshohocken, Pennsylvania; 2002.

[29] Hodgkinson JM (Editor). Mechanical testing of advance fiber composites, CRC Press, Boca Raton, California, 362 p; 2000.

[30] NP EN 12390-3:2011. Testing hardened concrete. Part 3: Compressive strength of test specimens. Instituto Português da Qualidade (IPQ), Caparica; 2011.

[31] RILEM TC 162-TDF. Test and design methods for steel fibre reinforced concrete. Materials and Structures 2002; 35: 579-582.

[32] CEN. Eurocode 2: Design of concrete structures - Part 1-1: General rules and rules for buildings. European Committee for Standardization (CEN), Brussels, 2004.

[33] Firmo JP, Correia JR, França P. Fire behaviour of reinforced concrete beams strengthened with CFRP laminates: Protection systems with insulation of the anchorage zones. Composites Part B: Engineering 2012; 43(3): 1545-1556.

[34] CEN. Eurocode 1: Actions on structures - Part 2: Traffic loads on bridges. European Committee for Standardization (CEN), Brussels; 2003.

[35] ARTeMIS Modal Pro. Structural Vibration Solutions; 2014. 
[36] SÉTRA. Assessment of vibrational behaviour of footbridges under pedestrian loading, Technical guide. Service d'études techniques des routes et autoroutes (SÉTRA); 2006.

[37] Thambiratnam DP, Perera NJ, Abeysinghe CM, Huang M, de Silva SS. Human activity-induced vibration in slender structural systems, Structural Engineering International 2012; 22(2): 238-245.

[38] CEN. Eurocode 0: Basis of structural design. European Committee for Standardization (CEN), Brussels; 2005.

[39] ISO 10137. Bases for design of structures - Serviceability of buildings and walkways against vibrations. International Organization for Standardization (ISO), Genève; 2007.

[40] Sá MF, Gomes AM, Correia JR, Silvestre N. Creep behaviour of pultruded GFRP elements - Part 1: Literature review and experimental study. Composite Structures 2011; 93(10): 2450-2459.

[41] Bank LC. Composites for construction: Structural design with FRP materials. John Wiley \& Sons, Inc., New Jersey, 2006.

[42] CEN. Eurocode 4: Design of composite steel and concrete structures - Part 1-1: General rules and rules for buildings. European Committee for Standardization (CEN), Brussels; 2004.

[43] Gonilha JA, Aquino A, Correia JR, Branco FA. Experimental evaluation of the GFRP/ECC connection - Shear connection tests: phase 1. ICIST internal project report A5.T4.IST.1. Instituto Superior Técnico, Technical University of Lisbon; 2010.

[44] Dutta PK, Hui D. Creep rupture of a GFRP composite at elevated temperatures. Computers and Structures 2000; 76(1-3): 153-61. 
[45] Sá MF, Gomes AM, Correia JR, Silvestre N. Creep behaviour of pultruded GFRP elements - Part 2: Analytical study. Composite Structures 2011; 93(9): 2450-2459. 


\section{Figures captions}

Figure 1 - Cross-section of the prototype and strain gauges at midspan.

Figure 2 - Geometry of the footbridge prototype: side view and cut view A-A (top) and main to secondary girders connection details (bottom) - dimensions in $\mathrm{mm}$.

Figure 3 - Construction of the prototype: (a) manufacturing the GFRP profiles; (b) Transportation of the GFRP component; (c) casting the SFRSCC deck; (d) applying the epoxy layer; (e) placing the GFRP grid; (f) placing the footbridge on the final position

Figure 4 - Static test: load configurations (a), (b) and (c).

Figure 5 - Perspective of the 3D finite element model and detail of an interior main to secondary girder connection.

Figure 6 - Modal identification test setups: acceleration measuring positions and orientation (dimensions in $\mathrm{mm}$ ).

Figure 7 - Modal identification test: accelerations over time for test setup 1.

Figure 8 - Modal identification test: setup 1 singular values decomposition for the reference sensors.

Figure 9 - Modal identification test: results of the first 16 mode shapes with ambient excitation.

Figure 10 - Transient response for damping estimation for the reference sensors.

Figure 11 - Pedestrian response tests: undergoing tests with several pedestrians.

Figure 12 - Pedestrian response tests: position of the accelerometers over the deck and motion paths.

Figure 13 - One pedestrian tests: accelerations attained at position A1 for the pedestrian 
walking normally in the centred and eccentric paths.

Figure 14 - Several pedestrian tests: comparison between the experimental expected vertical accelerations (RMS) and the ISO 10137 [39] limits for several periods of exposure.

Figure 15 - Structure loaded for the creep test.

Figure 16 - Temperature $(T)$ and relative humidity $(R H)$ registered during the creep test period.

Figure 17 - Creep deflections: experimental results, Findley's law regression and analytical predictions with $0.30 \leq n_{E} \leq 0.36$ and $992.85 \leq E_{t} \leq 1241.06 \mathrm{GPa}$.

Figure 18 - Creep deflections long-term predictions based on; Findley's law regression of short-term test results and; analytical predictions with $0.30 \leq n_{E} \leq 0.36$ and $992.85 \leq E_{t} \leq 1241.06 \mathrm{GPa}$. 


\section{Tables captions}

Table 1 - Mechanical properties of the GFRP main girders (avg. \pm std. dev.).

Table 2 - SFRSCC mix proportion per cubic meter $\left[\mathrm{kg} / \mathrm{m}^{3}\right]$.

Table 3 - Mechanical properties of the SFRSCC (avg. \pm std. dev.).

Table 4 - Average mid-span deflections $\left(\delta_{m s, A v g}\right)$, axial strains on the SFRSCC deck $\left(\varepsilon_{c, A v g}\right)$, GFRP webs $\left(\varepsilon_{w, A v g}\right)$ and bottom flanges $\left(\varepsilon_{f, A v g}\right)$, and curvature $(\chi)$ at midspan measured in the static tests, calculated with the FE model and corresponding relative difference $(\Delta)$.

Table 5 - Modal identification tests: frequency, damping ratio and mode nature.

Table 6 - Maximum accelerations registered in the one pedestrian experimental test (avg. \pm std. dev.). 